\title{
On the Role of Analogy Mechanism in Meaning Evolution of Chinese New Words
}

\author{
Jiang Tongxuan \\ College of Arts, China West Normal University, Nanchong, China \\ Email: jiangtongxuan2006@126.com
}

Received 19 June 2015; accepted 14 August 2015; published 18 August 2015

Copyright (C) 2015 by author and Scientific Research Publishing Inc.

This work is licensed under the Creative Commons Attribution International License (CC BY). http://creativecommons.org/licenses/by/4.0/

c) (i) Open Access

\begin{abstract}
The development of economy, the emergence of new things, and the change of traditional ideas have brought modern Chinese thousands upon thousands of new words, which are accordingly followed by constantly new meaning. Among the new words created by analogy, the common righteousness will change under the influence of whole semantic structure and different seme combinations. However, partial variation would gradually become stable and then progress into fresh sense owing to the frequent use of analogies in word-formation. Therefore, the text will be developed from the meaning influenced by analogy mechanism and the analysis of emotion.
\end{abstract}

\section{Keywords}

\section{Analogy Mechanism, New Words, Words Meaning Evolution, Function}

\section{Introduction}

The word "analogy” comes from the Greek word "analogos”, which means "regularity” or "proportional regularity". But the so-called "analogy mechanism” is to make some vocabularies and forms of language look up to others that have been regarded as the criteria, thus to build new phrases or forms.

The analogical change of language is universal. Historical comparative linguists explain the evolution of the pronunciation, lexicological, and grammar rules with the help of analogy mechanism. The study of the language's analogy mechanism will help us to reveal the system and stucture of language as well as the common laws of language use. From 1906 to 1911 in Geneva, Ferdinand de Saussure had referred to analogy mechanism in three courses. He viewed the superficial variation of any word that didn't belong to the nature of the speech was caused by analogy, which must have a model and a regular imitation of this model. The analogy form is the form constructed, with one or several other shapes as model, according to certain rules (de Saussure, 2002: pp. 226-227). Ferdinand de Saussure boiled the imitation procedures down to a four proportional (the Paul propor- 
tion) oratorem: orator = honorem: $\mathrm{x} ; \mathrm{x}=$ honor (de Saussure, 2002: p. 227). Using the four-proportion manner to interpret analogy-formation words is custom in the new grammar school. Each member of this school has used it to explain the phenomenon of language variation.

The change of analogy fully acts in Chinese, not only in lexical composition, voice evolution, but also in the development of word meaning. It is considered that the analogy of Chinese words, on one hand, is caused by the influence of the user's subjective thought to language, namely the users' psychological needs of seeking commonality, novelty, fashion and briefness; on the other hand, it is caused by the internal law of language development. The word-formation analogy in Chinese expression makes the new lexicons neat oriented, novel and fashionable. They are satisfying the physical requirements of conductors as well as simply to be understood and applied. Voice analogy is the subjective base of easy learning and remembrance. Sense analogy also has to meet users' demanding order and consistent meaning apart from facile mastery.

\section{The Logic and Linguistics Interpretation of Analogy Mechanism}

Analogy mechanism can reflect in artificial language, especially the semantic (propositional meaning) reduction of logical and natural language. But their principles are basically consistent, that is, deducing the conclusion (fresh meaning) from a certain premise (logic or context, natural language). And their common ground is the analogical mechanism of language.

\subsection{Analogical Inference in Logic}

Analogical inference is one of the usually reasoning methods in logic. When confronting new things or phenomena that need to be explained, people always try to find things that possess the factors in line with the current happenings from experiences, then infer the characteristic of current things with the knowledge of known objects. This is analogical reference (Chen, 1996), whose structure can be formulated (Peng, 2000) as:

If object $\mathrm{A}$ has the attributes of $\mathrm{a}, \mathrm{b}, \mathrm{c}, \mathrm{d}$

object B has the properties of a, b, c

Then object B has property of d, too.

In this formula, the properties a, b, c are commonly enjoyed by $\mathrm{A}$ and $\mathrm{B}$, so they are called common attributes; and the confirmed A's attribute d (whether B has this property or not is unknown) in the premise is identified is fit to $\mathrm{B}$ in conclusion. In this way, $\mathrm{d}$ is releasing property.

The base of analogical reasoning is the similarity between objective things. Therefore, if two things are the same or similar in a set of attributes, they may also be the same or similar in other attributes. Conclusions got in this way usually give rise to unexpected discoveries. Many inventions or discoveries are the results of analogical ratiocination. For instance, people create kites according to bird's flight, and invent aircraft based on the principle of the former invention; Newton launched the Law of universal gravitation after he had seen apples falling down to the ground rather than flying up.

However, such reasoning conclusion is not entirely reliable. The connection among objects is very complicated because if there are necessary links there must be occasional ones. Analogy inference is deducting on the base of relatively simple comparison, it does not analyze the relation between properties, so the conclusions are not necessarily correct.

\subsection{Analogical Inference in the Development of Language}

The analogical mechanism that has been talked about is closely related to the analogy inference in logic. Thus, it can be regarded as an extension to analogical reasoning in the theory of language acquisition. It roots from analogical reasoning but boasts its own connotation.

According to the basic structure of analogical inference, analogy structure in language study can be expressed as follow:

If language phenomenon A has the usage or ingredients a, b, c, d

language phenomenon $B$ has the usage or ingredients $a, b, c$

Then, language phenomenon $B$ has the usage or ingredient $d$, too. 
That is, if phrase A enjoys the usage a, b, c, d, and if B has the same uses of a, b, c, then it is likely that B has the use of $d$, too. In fact, analogy mechanism is the method of consciously employing language with analogical reasoning. Just like analogical reasoning, perorations reasoned from simple linkages among linguistic phenomena can be proper or improper. In language learning, the rightly reasoning conclusion allows learners to gain further knowledge and ability of language. But such reference is often misleading, and easily leads learners to create things that don't conform to the grammar specification of the target language. So, although Ferdinand de Saussure had realized the relationship between language and the external conditions of society, culture, institution, etc., he didn't use it to explain the causes why language can be or cannot be reasoned.

But the structural model of language that gathering together in the form of analogy reflects the gradual modeling process and the results of language phenomena in language development. Such as “adverb + noun”: very sunshine (means cheerful and optimistic), very woman (being full of feminine traits), very lady (gentlewomanly), etc., they had come into being in the early twentieth century, but it was not until the 80s and 90s did they become models through the power of analogy mechanism (Xing, 1997). The background of language analogy is the language itself. And in order to achieve language analogy, there must be a "model”, namely "category". Therefore, the form of analogy can only be deduced with one or more other forms as model, that is, category is the basis and starting point of reasoning. There exist a great number of such models (category), from morpheme to sentences (sentence models), in the world of language waited to be deduced. For example, neuter, number, case, tense, voice and other grammatical scopes in English are the categories of this model. For instance, the word "burriels (bury)"came from the ancient English word "byrgels" was singular, but it was later been recreated into the singular form as "burial funeral” on the model of (analogical function) "funeral”.

\section{Conditions for Analogy Mechanism to Generate New Words}

The replaceable exotic morpheme in the new words created by analogy mechanism is a kind of paradigmatic relation based on psychological association. Members of such relationship rely on identity and difference to make new expressions. "Continuous speech activities decompose the variously provided units. They themselves contain all the possibilities of not only speaking according to habits, but also reasoning” (de Saussure, 2002: p. 241). Theo-retically, "all the possibilities build by analogy" can produce countless isomorphic analogy words and phrases. Since the analogical vocabularies are "massively produced" based on certain fundamental forms, they never appear separately but always work with other foundation forms to construct phrase groups. The polymerization of different morpheme in these words semantically has similar meaning. Due to factors like morpheme ambiguity as well as sociability and culture of vocabulary, words that boast the same meaning on the surface may not belong to equal word group. On the other hand, clumps brought about by analogy must meet the following conditions:

1) The most striking feature of clumps in combination relation is that they have similar structure relationship, which is decided by basic forms. Such as "diet therapy, magnetic therapy, radiotherapy, chemotherapy, physiotherapy”, all the "therapies" in this group refer to "treatment”, and they are partial formal structure. Thus, a word family that has alike morpheme can be produced through the imitation and analogy of these words.

2) Due to some morphemes have more than one meaning, the same morpheme in a word group has to be semantically identical, otherwise this group is null. That is, same morpheme shares same semantics. For instance, "ball blindness, dance blindness, music blindness, literacy blindness (illiterate), color blindness", the first four words of "blindness" means "people who are ignorant in certain aspect" and they take the simile reference, while the last "blindness " means "being confused". Because these "blindness" are not totally the same in these words, the above expressions can not constitute a word group.

3) Even though the structural relationships are consistent and the shape-alike morphemes have same semantic meaning in a group of words, the locations of the morphemes are different; they cannot form a word group. That is to say the location of the same morpheme must be consistent. For example, "Dige and Dijie (taxi drivers), Miandi (van taxi), Bandi (tricycle taxi), Modi (motorcycle taxi)", though all the "Di” in above indicate "taxi”, and these expressions are partial formal structures, too, they cannot form a word group because the location of the same morphemes is inconsistent, thus the aggregation of the morpheme relation cannot be established.

4) Synonymity morpheme is the foundation of paradigmatic relations, which grants the collocation of identical morpheme imitativeness and transitivity. Namely, different morphemes have thesaurus relation. For instance, "national feet, national hand, national mouth and national face”, the first three words are associated with sports 
that relate to specific body parts within a country or masters in the art filed. However, the "national face”, despite "face” represents a body part and it seemingly has the semantic reference as "foot”, "hand” and "mouth”, the later, while building phrases with "national”, has metonymy significance respectively; but "national face” means one's face that possesses the typical characteristics of his or her country, and this phrase takes the common meaning of "face". Consequently, this group of vocabularies is unable to make clumps, but "national feet, national hand and national mouth" can build one.

In summary, the above four conditions are necessary for constituting a group of words, and only with these conditions, a group can be formed. Furthermore, with different morphemes in a word as the same morpheme, there will be diverse colonies, which share coincident structure relationship but belong to different word groups according to the base of producing new words. For example:

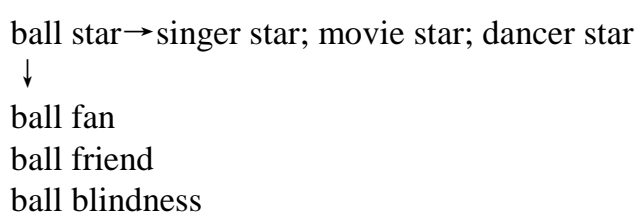

It shows that with "ball" and "star" as the identical morpheme respectively, one can invent the two vocabulary groups of "ball star, singer star, movie star, dancer star” and "ball star, ball fan, ball friend, ball blindness". They are all having partial formal structure relations. This also reflects from one side that analogy word-formation is extremely productive.

\section{The Role of Analogy Mechanism in the Semantic Evolution of Chinese New Words}

The development of economy, the emergence of new things with the change of traditional ideas have brought modern Chinese thousands upon thousands of fresh words, which accordingly followed by constantly new meaning. Among the new words created by analogy, the common righteousness will change under the influence of whole semantic structure and different seme combinations. However, partial variation would gradually become stable and then progress into novel sense owing to the frequent use of analogies in word-formation. Therefore, the text will be developed from the phrase meaning influenced by analogy mechanism and the analysis of emotion.

\subsection{The Influence of Semantic Analogy Word-Formation under Analogy Mechanism}

Many new words are constructed by using same or opposite semantic morpheme. Successful employment of such method is directly related to the mechanism of analogy. For example, the opposition of "soft index" and "hard index", "soft currency" and "hard currency", etc., is reasoned out from the pattern of "software" and "hardware". In fact, this is example of the semantic contrast, which plays an active role in word-formation and vitally impacts the significance of vocabularies.

Analogical change prefers regularity and ordering. The most advantageous foundation for analogy form in the process of word-formation is the derivative type that has definite meaning. The following discussion will be limited to new words created, according to certain rules of analogy, with the help of morpheme or words that have real meaning. To facilitate the title, one can name the common notional morpheme or vocabularies as basic meaning, while morpheme or words that make expressions with basic meaning the replacement seme. Coinage analogy is the way, on the base of fundamental glosseme, to make fresh terms with the combination of different alternatives glosseme respectively. Of course, this needs to obey certain common rules. As in "advertising package, calling package”, "package” is the foundation of righteousness, while "advertising, telephone” are the replacement of sememe. Analogy formation assembles the foundation with different alternatives to express new things, new concepts, etc.. The following analysis focuses on the impact of semantic analogy word-formation to the basic meaning under analogy mechanism. However, the lexical meaning of basis seme can also change owing to semantic constraints of replacing seme.

1) Seme shedding refers to the phenomenon that one sememe of basis glossemes sheds during the semantic analogy word-formation, leading to meaning variation in basic sense glosseme. It is the result of semantic interference in semantic combinations. 
Sememe shedding can be divided into two kinds according to the time of occurrence.

One is that the sememe fallen off before basis of the basic meaning combining into words, and analogy makes it "stationary", which leads to the meaning alteration caused by falling seme develops into new meaning upon the basic meaning. For example, the original meaning of "packages" is "collocation of food that supplied completely". However, when used in "advertising packages", the seme [+meals] of "packages" sheds from the basic meaning. In addition, analogy structures such as "Phone packages, family packages, cultural packages” as well as “cold perm, ceramic hot, ion hair technique” have further promoted this sememe's shedding.

Another is the seme of base glosseme in analogy-formation, when compared with the previous one, is off. For example, the "bar (pub)" is a transliteration of the English word "bar". After its introduction into modern Chinese, people have launched a series of trendy words, such as "Tao bar (places for selecting things usually in a cheap but functional way), net bar, bookstore bar, tea bar,” and so on. The significance in this analogy, the sememe [+drink] of "bar" falls, and it refers to the general term of places for leisure service establishments. Similar as "telephone service hotline, consultation hotline" and "tourism hotline", they are cases with basic meaning as the center.

In fact, sememe off also happens when the underlying meaning served as modifiers. For example, "junk" means "garbage or waste" and its basic meaning is [worthless and discarded]. But it is well known that "junk stocks” is not discarded stocks. Besides, “junk ads, junk Email (spam)” are not submitted into our mailbox due to man's misunderstanding as "junk”. In this group of analogy formation, the sememe [discarded] sheds and "junk" actually only highlights the "worthless" significance.

These examples show that, in the use of semantic word formed by analogy, people usually cause direct or indirect shedding in some seme of the foundation reference. The falling, in turn, makes it possible for the base combines with more replacements. They work mutually to add new seme or meaning to the basic meaning.

2) Meaning transformation indicates that while summing up things, the associative meaning of lexicon is implied. But after entering into sememe combination, these associations often prominent and even being repeatedly strengthened in the role of analogy's batching coinage. Thus, a semantic point progresses as one item. So people tend to take things contain certain properties to indicate the nature of things. Once such transformation becomes a regular usage owing to the action of analogy coinage, the words meaning would move forward, increasing new meaning that can express properties. For instance, the "golden" often reminds person of "valuable”, thus comes expressions as "golden places, golden time (prime)”. As one of the characteristics of "gold”-“precious” has gradually rose to another meaning in its repeated analogy. However, due to the nature of things is multidimensional, which provides human various feelings in different contexts, inversion based on fundamental meaning does not necessarily have equal reference in analogy words.

Of course, whether semantic dropping or meaning inversion, it is the significance variants of basic meaning in dynamic contexts. These variations can become a new sense or not depends on the presenting frequency of the based indication and how long it's employment. The semantic word formed by analogy is undoubtedly providing an opportunity for building fresh sense. Such new words are not difficult to be mastered because they share same structure with semantic relation of analogy. The rhetorical devices of the simulation wherein also make this kind of words full of feelings, thus they are rather popular.

\subsection{The Emotion of Semantic Analogy Word-Formation under Analogy Mechanism}

Emotion is the general reflection of the non-essential attributes of the objective objects. It is an important part of meaning and can express the speaker's feelings and attitudes. Hence human have granted language certain emotional tendencies and styles in linguistic usage, so that langue covers a layer of emotional coloring apart from its ration. The emotional affection of the semantic analogy word-formation in analogy mechanism is mainly reflected in the change of affection by varying the meaning of foundation. For example, "fool" originally meant "idiot", but since the import of "foolproof", people have faked out "fool code, fool computer, fool technology" and other expressions. In this way, not only the meaning of "fool” in these words develops into "simplicity and convenience”, but its negative emotion turns into positive.

When the indication of foundation changed during reasoning, emotional color will be changed accordingly. Such as "Pa (just like bully or hegemony)" means "people who rely on power and influence to oppress others or forcibly occupy others' belongings" in Standard Dictionary of Modern Chinese. It is a derogatory term. In recent years, however, one can often see or hear the expression of "XXX Pa", which includes two types of refer- 
ence. One is mainly about scoundrels or tyrants of certain industry, such as "electric Pa, water Pa, road Pa, vegetable Pa”. Another kind is mainly used for goods, referring to a series of products, such as "colorful Pa" in the $\mathrm{TV}$, “cool $\mathrm{Pa}$ ” in air conditioning, "solving Pa” in computer decompression, "vocabulary Pa” in the English learning software, "sound $\mathrm{Pa}$ ” in blaster, "noodle $\mathrm{Pa}$ ” in the instant noodles, "bath $\mathrm{Pa}$ " in the shower, etc..

In the former usage, the term "Pa" is a derogatory, referring to rude acts and is unreasonable. But in "colorful $\mathrm{Pa}$, cool $\mathrm{Pa}$, solving $\mathrm{Pa}$, vocabulary $\mathrm{Pa}$, sound $\mathrm{Pa}$, noodle $\mathrm{Pa}$ and bath $\mathrm{Pa}$ ", "Pa" simply stresses "huge and outstanding”. At the same time, its emotion is compliment.

Semantic analogy word-formation in the analogy mechanism is the product of man's seeking simple and innovative expressions, exhibiting the thinking means of analogy and innovation. It is not necessary for people to create new words when confronted with strange things or concepts, but rather to follow certain old words or patterns. Men are encouraged to express much more relevance with limited words. In addition, for the requirement of vivid and distinctive statements, human beings would bring ancient lexicons as well as their models to fresh speaking circumstance so as to create unconventional combinations. This changes the meaning of old righteousness, and expands its applicable areas and capacity.

The variation of word meaning in semantic analogy reflects the connection between word meaning and language use. Every word conduction produces more or less meaning "variation" for the specific context is different. But because the variation is temporary in certain language environment, it must be tested in speech application in order to integrate in meaning system. Only these who are relatively stable, smoothly expressive and widely recognized meaning can be recycled, maintained and extended. Although the transmission of lexical and grammatical meaning as well as emotion in Chinese words or morphemes is not entirely the result of analogy, analogy coinage is no doubt playing an active role, directly or indirectly. It has promoted the development and variation of lexical meaning. What's more, such effect is comprehensive, multi-angle and subject to our in-depth study.

\section{Funding}

The paper is supported by "the Start up Funds for Doctors” of China West Normal University (No. 14E010) and "the Specially Commissioned Research Funds of the Chongqing Federation of Social Science Circles” (No. 2014TBWT02-2).

\section{References}

de Saussure, B. F. (2002). Putong yuyanxue jiaocheng 普通语言学教程. Beijing: The Commercial Press.

Chen Yinghe 陈英和 (1996). Renzhi fazhan xinli xue 认知发展心理学. (pp. 263). Hangzhou: Zhejiang People’s Publishing House.

Peng Lianyi 彭涟渏 (2000). Luoji xue daolun 逻辑学导论. (pp. 333). Shanghai: East China Normal University press.

Xing Fuyi 刑福义 (1997). “Hen shunv” zhilei shuofa yuyan shehui wenhua beijing de sikao “很淑女”之类说法语言社会 文化背景的思考. The Study of Language, 2, 1-10. 